\title{
Analytical solutions for one-dimensional advection- dispersion equation of the pollutant concentration
}

\author{
Ali S Wadi*, Mourad F Dimian and Fayez N Ibrahim \\ Department of Mathematics, AinShams University, Cairo 0020, Egypt. \\ ${ }^{*}$ Corresponding author.e-mail: ali.wadi4@gmail.com
}

We present simple analytical solutions for the unsteady advection-dispersion equations describing the pollutant concentration $C(x, t)$ in one dimension. The solutions are obtained by using Laplace transformation technique. In this study we divided the river into two regions $x \leq 0$ and $x \geq 0$ and the origin at $x=0$. The variation of $C(x, t)$ with the time $t$ from $t=0$ up to $t \rightarrow \infty$ (the steady state case) is taken into account in our study. The special case for which the dispersion coefficient $D=0$ is studied in detail. The parameters controlling the pollutant concentration along the river are determined.

\section{Introduction}

It is well known in real situations, rivers are polluted by various kinds of pollutants coming from household and industrial sources (Shukla et al. 2008). Pollution of rivers has become a matter of concern for scientists working in environmental engineering, hydrology, chemical engineering, geology, soil physics, and mathematics. Analytical solutions of the mathematical models describing pollutant transport are rarely possible if important hydraulic and chemical processes are considered together (Massabo et al. 2006). Mathematical models have been used extensively to predict water quality and to provide reliable tools for water quality management in affected areas.

The particular river whose water quality was the motivation for this study is the Tha Chin River in Thailand (Pimpunchat et al. 2007). It is assumed that the pollutants are largely biological wastes, which undergo various biochemical and biodegradation processes using dissolved oxygen (Pimpunchat et al. 2007). Analytical solutions for one-dimensional transport in composite media are often derived with Laplace transforms (Carslaw and Jaeger 1959) and sometimes with Green's functions. Adjoin solution techniques and finite integral transform solutions are obtained by Mikhailov and Ozisik (1984) and Leij and Van Genuchten (1995). Van Genuchten and Alves (1982) and Ge and $\mathrm{Lu}$ (1996) provided analytical solutions for a physical system with zero initial concentration in a semi-infinite domain.

The explicit finite difference method is found to be effective and accurate for solving the one and two-dimensional advection-dispersion equations with variable coefficients in semi-infinite media. Also it can be used with arbitrary initial and boundary conditions, as well as with different variations of dispersion and velocity, for which analytical solutions are not available (Djordjevich and Savovic 2013; Savovic and Djordjevich 2012, 2013; Savovic and Caldwell 2003, 2009).

The objective of this study is to develop analytical solutions of one-dimensional unsteady

Keywords. Pollutant; concentration; Laplace transformation; dispersion. 
state advection dispersion flow equation by using the method of Laplace transforms. Our results generalize the earlier solutions obtained by Pimpunchat et al. (2007), which form a subset of our solutions, for the limited case when $t \rightarrow \infty$.

\section{Formulation of the problem}

Consider the unsteady flow in a river as being onedimensional characterized by a single spatial distance $x(\mathrm{~m})$ measured from the source of the river. The water pollution or the concentration of the pollutant $C(x, t)$ is assumed to vary with time $t$ (days) along the length of the river and is treated as homogeneous across the river cross section (Dobbins 1964; Pimpunchat et al. 2009).

The river has been divided into two regions: upstream $x \leq 0$ near the source, where it is assumed that the rate of pollutant addition along the river $q(\mathrm{~kg} / \mathrm{m} \cdot$ day $)$ vanishes, and downstream $0 \leq x<L(\mathrm{~m})$ (the polluted length of the river), where $q=$ const. The equations governing onedimensional advective-dispersive transport can be written as (Pimpunchat et al. 2009):

$$
\begin{aligned}
\frac{\partial\left(A C_{1}\right)}{\partial t}= & D \frac{\partial^{2}\left(A C_{1}\right)}{\partial x^{2}}-\frac{\partial\left(v A C_{1}\right)}{\partial x} \\
& -k_{1} \frac{X}{X+k} A C_{1}, \quad x \leq 0, t>0 \\
\frac{\partial\left(A C_{2}\right)}{\partial t}= & D \frac{\partial^{2}\left(A C_{2}\right)}{\partial x^{2}}-\frac{\partial\left(v A C_{2}\right)}{\partial x} \\
& -k_{1} \frac{X}{X+k} A C_{2}+q \\
& 0 \leq x<L \leq \infty, t>0
\end{aligned}
$$

where $C_{1}$ and $C_{2}$ are the concentrations of the pollutant in the two regions respectively $\left(\mathrm{kg} \cdot \mathrm{m}^{-3}\right)$, $A$ is the cross section area of the river $\left(\mathrm{m}^{2}\right), D$ is the dispersion coefficient of pollutant in $x$ direction $\left(\mathrm{m}^{2} \cdot\right.$ day $\left.^{-1}\right), v$ is the water velocity in the $x$ direction $\left(\mathrm{m} \cdot\right.$ day $\left.^{-1}\right), k_{1}$ is the degradation rate coefficient for pollutant $\left(\right.$ day $\left.^{-1}\right), k$ is the half-saturated oxygen demand concentration for pollutant decay $\left(\mathrm{kg} \cdot \mathrm{m}^{-3}\right), X(x, t)$ is the concentration of the dissolved oxygen within the river $\left(\mathrm{kg} \cdot \mathrm{m}^{-3}\right)$. For convenience, the stream reach is considered to be a homogeneous system, so that all parameters such as $A, D, v, k_{1}, q$ hold constant values over time and space ( $\mathrm{Li} 2006$ ). In the general case when the half-saturated oxygen demand concentration for pollutant decay $k \neq 0$, it will be impossible to use Laplace transform to suggest an exact solution. In this paper by taking $k=0$, we can apply the Laplace transformation and obtain the solution. The initial and boundary conditions associated with equations (1 and 2) are (Pimpunchat et al. 2009):

$$
\begin{gathered}
C_{1}(x, 0)=C_{2}(x, 0)=0, \\
C_{1}(0, t)=C_{2}(0, t), \quad t>0, \\
\frac{d C_{1}(0, t)}{d x}=\frac{d C_{2}(0, t)}{d x}, \quad t>0 .
\end{gathered}
$$

\section{The analytical solution}

Laplace transformation technique is defined by equation (6), and is used to get the analytical solutions. The Laplace transformation may be defined as:

If $f(x, t)$ is any function defined in $a \leq x \leq b$ and $t>0$, then its Laplace transform with respect to $t$ is denoted by:

$$
L\{f(x, t)\}=F(x, p)=\int_{0}^{\infty} e^{-p t} f(x, t) d t, \quad p \succ 0
$$

where $p$ is called the transform variable (Doetsch 1970; Kumar et al. 2011). The inverse Laplace transformation is denoted by $L^{-1}\{F(x, p)\}=$ $f(x \cdot t)$ and defined by the complex variable:

$$
\begin{aligned}
L^{-1}\{F(x, p)\} & =f(x, t) \\
& =\frac{1}{2 \pi i} \int_{c-i \infty}^{c+i \infty} F(x, p) e^{-p t} d p \quad c \succ 0 .
\end{aligned}
$$

Applying Laplace transformation to equations (1 and 2) gives:

$$
\begin{aligned}
& D \frac{d^{2} \tilde{C}_{1}(x, p)}{d x^{2}}-v \frac{d \tilde{C}_{1}(x, p)}{d x}+C_{1}(x, 0) \\
& -\left(k_{1}+p\right) \tilde{C}_{1}(x, p)=0, \quad x \leq 0, p>0, \\
& D \frac{d^{2} \tilde{C}_{2}(x, p)}{d x^{2}}-v \frac{d \tilde{C}_{2}(x, p)}{d x}+C_{2}(x, 0) \\
& -\left(k_{1}+p\right) \tilde{C}_{2}(x, p)+\frac{q}{A p}=0, \quad x \geq 0, p>0 .
\end{aligned}
$$

The boundary conditions (4 and 5) in the Laplace domain are:

$$
\begin{array}{r}
\tilde{C}_{1}(0, p)=\widetilde{C}_{2}(0, p), \\
\frac{d \widetilde{C}_{1}(0, p)}{d x}=\frac{d \widetilde{C}_{2}(0, p)}{d x} .
\end{array}
$$


By using equation (3), the solutions of equations (7 and 8) are given by:

$$
\begin{aligned}
\tilde{C}_{1}(x, p)= & \frac{D}{\left(k_{1}+p\right)} \cdot \alpha_{1} \exp [x(\delta+\sqrt{(\alpha+p) / D})] \\
& +\frac{D}{\left(k_{1}+p\right)} \cdot \alpha_{2} \exp [x(\delta-\sqrt{(\alpha+p) / D})], \\
\tilde{C}_{2}(x, p)= & \frac{q}{A p\left(k_{1}+p\right)} \\
& +\frac{D}{\left(k_{1}+p\right)} \cdot \alpha_{3} \exp [x(\delta+\sqrt{(\alpha+p) / D})] \\
& +\frac{D}{\left(k_{1}+p\right)} \cdot \alpha_{4} \exp [x(\delta-\sqrt{(\alpha+p) / D})],
\end{aligned}
$$

where $\alpha_{1}, \alpha_{2}, \alpha_{3}, \alpha_{4}$ are constants. To determine the constants $\alpha_{1}, \alpha_{2}, \alpha_{3}, \alpha_{4}$, we use the boundary conditions (9) and (10). Hence, equations (10.a) and (10.b) are given by:

$$
\begin{aligned}
& \tilde{C}_{1}(x, p)=\frac{q}{A p\left(k_{1}+p\right)}\left(\frac{\sqrt{(\alpha+p) / D}-\delta}{2 \sqrt{(\alpha+p) / D}}\right) \\
& \times\{\exp [x(\delta+\sqrt{(\alpha+p) D})]\}, \quad x \leq 0, \quad \\
& \widetilde{C}_{2}(x, p)=\frac{q}{A p\left(k_{1}+p\right)} \\
& \quad-\frac{q}{A p\left(k_{1}+p\right)}\left(\frac{\delta+\sqrt{(\alpha+p) / D}}{2 \sqrt{(\alpha+p) / D}}\right) \\
& \quad \times\{\exp [x(\delta-\sqrt{(\alpha+p) / D})]\}, \quad x \geq 0
\end{aligned}
$$

where

$$
\alpha=D \beta^{2}, \quad \delta=\frac{v}{2 D}, \quad \beta=\sqrt{\delta^{2}+\frac{k_{1}}{D}} .
$$

The inverse of equations (11 and 12) have been obtained by taking the inverse of each of them using the inverse Laplace transformation and applying the convolution theorem and shift theorem (Roberts and Kaufman 1969). Thus, $C_{1}(x, t)$ and $C_{2}(x, t)$ are given by:

$$
\begin{aligned}
& C_{1}(x, t) \\
& =\frac{q}{4 k_{1} A}\{\exp [(\delta-\beta) x]\} \operatorname{erfc}\left(\frac{-x}{2 \sqrt{D} t}+\sqrt{\alpha t}\right) \\
& \quad+\frac{q}{4 k_{1} A}\{\exp [(\delta+\beta) x]\} \operatorname{erfc}\left(\frac{-x}{2 \sqrt{D t}}-\sqrt{\alpha t}\right) \\
& \quad-\frac{q}{2 k_{1} A}\left\{\exp \left[-k_{1} t\right]\right\} \operatorname{erfc}\left(\frac{-x}{2 \sqrt{D} t}+\sqrt{\left(\alpha-k_{1}\right) t}\right)
\end{aligned}
$$

$$
\begin{aligned}
& -\frac{q}{4 k_{1} A} \frac{\delta}{\beta}\{\exp [(\delta+\beta) x]\} \operatorname{erfc}\left(\frac{-x}{2 \sqrt{D} t}-\sqrt{\alpha t}\right) \\
& +\frac{q}{4 k_{1} A} \frac{\delta}{\beta}\{\exp [(\delta-\beta) x]\} \operatorname{erfc}\left(\frac{-x}{2 \sqrt{D t}}+\sqrt{\alpha t}\right), \\
& x \leq 0,
\end{aligned}
$$

$$
\begin{aligned}
C_{2}(x, t) & \frac{q}{k_{1} A}-\frac{q}{k_{1} A}\left\{\exp \left[-k_{1} t\right]\right\} \\
& -\frac{q}{4 k_{1} A} \frac{\delta}{\beta}\{\exp [(\delta-\beta) x]\} \operatorname{erfc}\left(\frac{x}{2 \sqrt{D t}}-\sqrt{\alpha t}\right) \\
& +\frac{q}{4 k_{1} A} \frac{\delta}{\beta}\{\exp [(\delta+\beta) x]\} \operatorname{erfc}\left(\frac{x}{2 \sqrt{D} t}+\sqrt{\alpha t}\right) \\
& +\frac{q}{2 k_{1} A}\left\{\exp \left[-k_{1} t\right]\right\} \operatorname{erfc}\left(\frac{x}{2 \sqrt{D} t}-\sqrt{\left(\alpha-k_{1}\right) t}\right) \\
& -\frac{q}{4 k_{1} A}\{\exp [(\delta+\beta) x]\} \operatorname{erfc}\left(\frac{x}{2 \sqrt{D t}}+\sqrt{\alpha t}\right) \\
& -\frac{q}{4 k_{1} A}\{\exp [(\delta-\beta) x]\} \operatorname{erfc}\left(\frac{x}{2 \sqrt{D} t}-\sqrt{\alpha t}\right), \\
& x \geq 0 .
\end{aligned}
$$

It is generally more convenient to work with models written in dimensionless variables, by employing the following definitions:

$$
\begin{aligned}
& t^{*}=k_{1} t, \quad x^{*}=\frac{k_{1} x}{v}, \quad C_{1}^{*}=\frac{C_{1}}{\left(q / k_{1} A\right)}, \\
& C_{2}{ }^{*}=\frac{C_{2}}{\left(q / k_{1} A\right)}, \quad D^{*}=\frac{k_{1} D}{v^{2}}, \quad \delta^{*}=\delta\left(\frac{v}{k_{1}}\right), \\
& \beta^{*}=\beta\left(\frac{v}{k_{1}}\right),
\end{aligned}
$$

where $(*)$ denotes dimensionless quantity. Hence, equations (14) and (15) take the form:

$$
\begin{aligned}
& C_{1}^{*}\left(x^{*}, t^{*}\right) \\
& =\frac{1}{4}\left\{\exp \left[\left(\delta^{*}-\beta^{*}\right) x^{*}\right]\right\} \operatorname{erfc}\left(\frac{-x^{*}+2 D^{*} \beta^{*} t^{*}}{2 \sqrt{D^{*} t^{*}}}\right) \\
& +\frac{1}{4}\left\{\exp \left[\left(\delta^{*}+\beta^{*}\right) x^{*}\right]\right\} \operatorname{erfc}\left(\frac{-x^{*}-2 D^{*} \beta^{*} t^{*}}{2 \sqrt{D^{*} t^{*}}}\right) \\
& \quad-\frac{1}{2}\left\{\exp \left[-t^{*}\right]\right\} \operatorname{erfc}\left(\frac{-x^{*}+2 D^{*} \delta^{*} t^{*}}{2 \sqrt{D^{*} t^{*}}}\right) \\
& -\frac{\delta^{*}}{4 \beta^{*}}\left\{\exp \left[\left(\delta^{*}+\beta^{*}\right) x^{*}\right]\right\} \operatorname{erfc}\left(\frac{-x^{*}-2 D^{*} \beta^{*} t^{*}}{2 \sqrt{D^{*} t^{*}}}\right) \\
& +\frac{\delta^{*}}{4 \beta^{*}}\left\{\exp \left[\left(\delta^{*}-\beta^{*}\right) x^{*}\right]\right\} \operatorname{erfc}\left(\frac{-x^{*}+2 D^{*} \beta^{*} t^{*}}{2 \sqrt{D^{*} t^{*}}}\right), \\
& x^{*} \leq 0,
\end{aligned}
$$




$$
\begin{aligned}
& C_{2}^{*}\left(x^{*}, t^{*}\right) \\
& =1-\exp \left[-t^{*}\right] \\
& -\frac{\delta^{*}}{4 \beta^{*}}\left\{\exp \left[\left(\delta^{*}-\beta^{*}\right) x^{*}\right]\right\} \operatorname{erfc}\left(\frac{x^{*}-2 D^{*} \beta^{*} t^{*}}{2 \sqrt{D^{*} t^{*}}}\right) \\
& +\frac{\delta^{*}}{4 \beta^{*}}\left\{\exp \left[\left(\delta^{*}+\beta^{*}\right) x^{*}\right]\right\} \operatorname{erfc}\left(\frac{x^{*}+2 D^{*} \beta^{*} t^{*}}{2 \sqrt{D^{*} t^{*}}}\right) \\
& +\frac{1}{2}\left\{\exp \left[-t^{*}\right]\right\} \operatorname{erfc}\left(\frac{x^{*}-2 D^{*} \delta^{*} t^{*}}{2 \sqrt{D^{*} t^{*}}}\right) \\
& \quad-\frac{1}{4}\left\{\exp \left[\left(\delta^{*}+\beta^{*}\right) x^{*}\right]\right\} \operatorname{erfc}\left(\frac{x^{*}+2 D^{*} \beta^{*} t^{*}}{2 \sqrt{D^{*} t^{*}}}\right) \\
& \quad-\frac{1}{4}\left\{\exp \left[\left(\delta^{*}-\beta^{*}\right) x^{*}\right]\right\} \operatorname{erfc}\left(\frac{x^{*}-2 D^{*} \beta^{*} t^{*}}{2 \sqrt{D^{*} t^{*}}}\right), \\
& x^{*} \geq 0 .
\end{aligned}
$$

From equations (16 and 17), it is clear that both $C_{1}^{*}$ and $C_{2}^{*}$ depend on only two parameters $q / k_{1} A$ and $\delta^{*}$, where

$$
\beta^{*}=\sqrt{\delta^{*^{2}}+2 \delta^{*}}, \quad D^{*}=\frac{1}{2 \delta^{*}} .
$$

\subsection{Special cases}

The steady state solution is obtained from equations (14) and (15) by taking the limit $t \rightarrow \infty$. Hence, in this case $C_{1}(x)$ and $C_{2}(x)$ take the form:

$$
\begin{aligned}
& C_{1}(x)=\frac{q}{k_{1} A}\left(\frac{\beta-\delta}{2 \beta}\right)\{\exp [(\delta+\beta) x]\}, \quad x \leq 0, \\
& C_{2}(x)=\frac{q}{k_{1} A}\left(1-\left(\frac{\delta+\beta}{2 \beta}\right)\right)\{\exp [(\delta-\beta) x]\}, \quad x \geq 0,
\end{aligned}
$$

equations (18 and 19) are the same as those obtained by Pimpunchat et al. (2009), (equation 3.7).

\subsection{Model including time and zero dispersion}

In practice, for pollutants such as insoluble carbon sized much larger than $0.45 \mu \mathrm{m}$ and with an anomalous shape indicating that the radius of the diffusing pollutant $r \gg 0$, then $D$ may be approximately zero (Angelakis and Rolston 1985), for this case equation (2) reduces to:

$$
\frac{\partial\left(A C_{3}\right)}{\partial t}=-\frac{\partial\left(v A C_{3}\right)}{\partial x}-k_{1} A C_{3}+q, \quad x \geq 0,
$$

the initial and boundary conditions are:

$$
\begin{gathered}
C_{3}(x, 0)=p_{1}, \quad x \geq 0, \\
C_{3}(0, t)=p_{2}, \quad t>0,
\end{gathered}
$$

where $C_{3}(x, t)$ is the pollutant concentration for the special case when the dispersion coefficient $D=0$, $p_{1}$ and $p_{2}$ are the initial rate of pollution $\left(\mathrm{kg} \mathrm{m}^{-3}\right)$ along the river and the rate of pollution $\left(\mathrm{kg} \mathrm{m}^{-3}\right)$ at the origin respectively. For this case, there is no pollution in upstream for the absence of dispersion, i.e., $\left(C_{3}(x, t)=0\right.$ for $\left.x<0\right)$. We will use Laplace transform technique to solve equation (20) subject to initial condition (21) and boundary condition (22). Applying Laplace transformation to governing equation (20) and incorporating the boundary condition (22) gives:

$$
\begin{aligned}
p \widetilde{C}_{3}(x, p)-C_{3}(x, 0)= & -v \frac{\partial \widetilde{C}_{3}(x, p)}{\partial x}-k_{1} \widetilde{C}_{3}(x, p) \\
& +\frac{q}{A p}, \quad p>0 \\
\tilde{C}_{3}(0, p)= & \frac{p_{2}}{p} .
\end{aligned}
$$

By using equation (21), equation (23) can be written as:

$\frac{\partial \tilde{C}_{3}(x, p)}{\partial x}+\left(\frac{k_{1}+p}{v}\right) \tilde{C}_{3}(x, p)=\frac{1}{v}\left(p_{1}+\frac{q}{A p}\right), \quad p>0$,

where $p$ is the Laplace transform variable. The general solution of equation (25) is:

$$
\begin{aligned}
\tilde{C}_{3}(x, p)= & \left(\frac{q}{A p}+p_{1}\right) \frac{1}{\left(k_{1}+p\right)} \\
& +\alpha_{5}\left\{\exp \left[-\left(\frac{k_{1}+p}{v}\right) x\right]\right\},
\end{aligned}
$$

where $\alpha_{5}$ is arbitrary constant. Applying the condition (24) to equation (26), we get:

$$
\begin{aligned}
\tilde{C}_{3}(x, p)= & \frac{q}{A p\left(k_{1}+p\right)}+\frac{p_{1}}{k_{1}+p} \\
& -\frac{q}{A p\left(k_{1}+p\right)}\left\{\exp \left[-\left(\frac{k_{1}+p}{v}\right) x\right]\right\} \\
& -\frac{p_{1}}{k_{1}+p}\left\{\exp \left[-\left(\frac{k_{1}+p}{v}\right) x\right]\right\} \\
& +\frac{p_{2}}{p}\left\{\exp \left[-\left(\frac{k_{1}+p}{v}\right) x\right]\right\} .
\end{aligned}
$$

The inverse of Laplace transform of equation (27) is:

$$
\begin{gathered}
C_{3}(x, t)=\frac{q}{A}\left(\frac{1}{k_{1}}-\frac{1}{k_{1}}\left\{\exp \left[-\left(k_{1} t\right)\right]\right\}\right) \\
+p_{1}\left\{\exp \left[-\left(k_{1} t\right)\right]\right\}
\end{gathered}
$$




$$
\begin{aligned}
& -\frac{q}{A}\left(\frac{1}{k_{1}}-\frac{1}{k_{1}}\left\{\exp \left[-\left(k_{1} t\right)\right]\right\}\right) \\
& \otimes\left(\exp \left[-\left(\frac{k_{1}}{v}\right) x\right] H\left(t-\frac{x}{v}\right)\right) \\
& -p_{1}\left\{\exp \left[-\left(\left(\frac{k_{1}}{v}\right) x+k_{1} t\right)\right] H\left(t-\frac{x}{v}\right)\right\} \\
& +p_{2}\left\{\exp \left[-\left(\frac{k_{1}}{v}\right) x\right] H\left(t-\frac{x}{v}\right)\right\},
\end{aligned}
$$

where $H(t-x / v)$ is Heaviside function, defined by:

$$
\begin{aligned}
H\left(t-\frac{x}{v}\right)=1 & \text { if } t>\frac{x}{v}, \\
0 & \text { if } t<\frac{x}{v},
\end{aligned}
$$

and $\otimes$ denotes the multiplication operation in the convolution theorem (Sudicky and Neville 2008). By using the convolution theorem equation (28) gives:

$$
\begin{aligned}
C_{3}(x, t)= & \frac{q}{k_{1} A}-\frac{q}{k_{1} A}\left\{\exp \left[-\left(k_{1} t\right)\right]\right\} \\
& +p_{1}\left\{\exp \left[-\left(k_{1} t\right)\right]\right\}-\frac{q}{k_{1} A}\left\{\exp \left[-\left(\frac{k_{1}}{v}\right) x\right]\right\} \\
& +\frac{q}{k_{1} A}\left\{\exp \left[-\left(\frac{k_{1}}{v} x+k_{1} t\right)\right]\right\} \\
& -p_{1}\left\{\exp \left[-\left(\frac{k_{1}}{v} x+k_{1} t\right)\right]\right\} \\
& +p_{2}\left\{\exp \left[-\left(\frac{k_{1}}{v}\right) x\right]\right\}, \quad t>\frac{x}{v} .
\end{aligned}
$$

To write equation (30) in dimensionless form we use the following dimensionless variables:

$$
\begin{gathered}
x^{*}=\frac{k_{1}}{v} x, \quad t^{*}=k_{1} t, \quad C_{3}^{*}\left(x^{*}, t^{*}\right)=\frac{C_{3}(x, t)}{\left(q / k_{1} A\right)}, \\
p_{1}^{*}=\frac{p_{1}}{\left(q / k_{1} A\right)}, \quad p_{2}^{*}=\frac{p_{2}}{\left(q / k_{1} A\right)},
\end{gathered}
$$

where $\left(v / k_{1}\right)$ scale for length and $q / k_{1} A$ scale for concentration. Hence, equation (30) becomes:

$$
\begin{aligned}
C_{3}^{*}\left(x^{*}, t^{*}\right)= & 1-\exp \left[-t^{*}\right]+p_{1}^{*} \exp \left[-t^{*}\right] \\
& -\exp \left[-x^{*}\right]+\exp \left[-\left(x^{*}+t^{*}\right)\right] \\
& -p_{1}^{*}\left\{\exp \left[-\left(x^{*}+t^{*}\right)\right]\right\} \\
& +p_{2}^{*}\left\{\exp \left[-x^{*}\right]\right\} .
\end{aligned}
$$

From equation (32), it is obvious that $C_{3}^{*}\left(x^{*}, t^{*}\right)$ depends on two dimensionless parameters $p_{1}^{*}$ and $p_{2}^{*}$ only.

\subsection{Steady-state case}

Equation (30) for the steady state when $t \rightarrow \infty$, gives:

$$
\begin{gathered}
C_{3}(x)=\frac{q}{k_{1} A}-\frac{q}{k_{1} A}\left\{\exp \left[-\left(\frac{k_{1}}{v}\right) x\right]\right\} \\
+p_{2}\left\{\exp \left[-\left(\frac{k_{1}}{v}\right) x\right]\right\} .
\end{gathered}
$$

For the special case, when $p_{2}=0$, equation (33) will be the same as that obtained by Pimpunchat et al. (2009).

\section{Results and discussions}

We present simple analytical solutions for the unsteady advection dispersion equations describing the pollutant concentration $C(x, t)$ in one dimension using Laplace transformation method. From solutions we obtained variation of $C_{1}, C_{2}$, and $C_{3}$ with time and space. The time is given in days and the values of the concentration of pollutant are measured in $\mathrm{kg} \mathrm{m}^{-3}$. In general, the pollutant concentration is given by equations (14, 15 and 30).

The analytical solutions obtained previously by Pimpunchat et al. (2007) ignored the solution in the important interval of the time $t$, where $0 \leq t<$ $\infty$. The importance of the solution in this period is due to the fact that the remediation by aeration occurs in this period of time $t$, before the pollutant concentration reaches its maximum value as $t \rightarrow$ $\infty$. The main achievement of our paper is that we obtained the pollutant concentration at any instant of the time $t$ in the period $0 \leq t \leq \infty$.

Figure 1 shows the variation of $\left(C_{1}, C_{2}\right)$ in the range $-10 \leq x \leq 20(\mathrm{~m})$ with the time $t$ for the

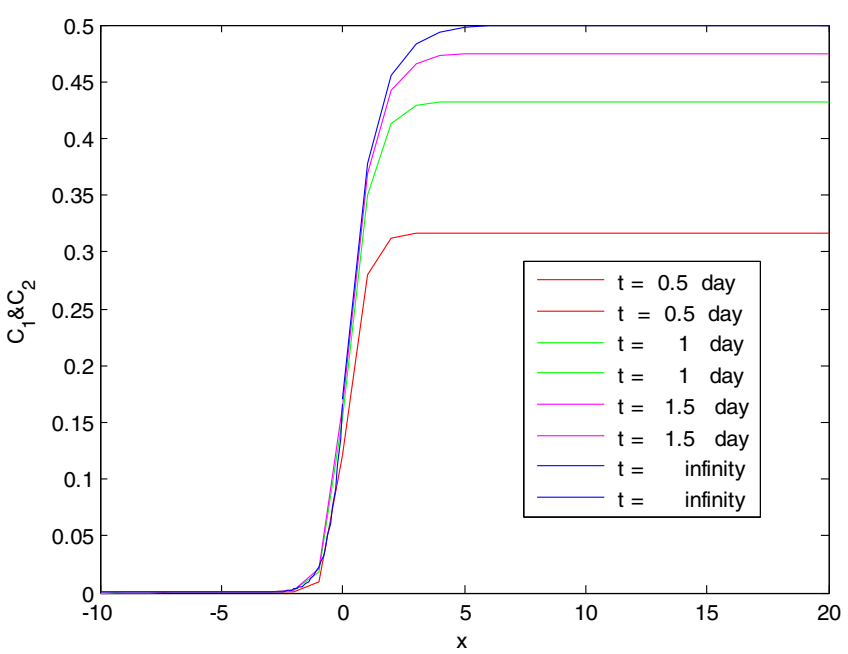

Figure 1. Shows the analytical unsteady state solution with dispersion for $C_{1}(x, t)$ and $C_{2}(x, t)$ at different time described by equations $(14,15)$. 
case when $D \neq 0$, described by equations (14) and (15) for $t=0.5,1.0,1.5$ (days) and $t \rightarrow \infty$. To test our model, the parameters $A, v, q$ and $D$ are taken to be equal to 1 and $k_{1}$ is equal to 2 (Pimpunchat et al. 2007). From figure 1, it is clear that:

For $x \leq 0$, the time $t$ has very small effect on $C_{1}$. For $x \geq 0$ as $t$ increases $C_{2}$ increases and reaches its maximum value as $t \rightarrow \infty$.

The values of $C_{1}$ and $C_{2}$ at the steady state as $t \rightarrow \infty$, coincide with that obtained by Pimpunchat et al. (2007).

In general, the concentration of pollutant increases as $x$ increases from upstream to downstream. This result is in good agreement with that reported by Kumar et al. (2009) and Mourad et al. (2013).

Figure 2 shows the variation of $C_{1}^{*}\left(x^{*}, t^{*}\right)$ and $C_{2}^{*}\left(x^{*}, t^{*}\right)$ given by equations (16), (17) with $\delta^{*}$ where $\delta^{*}=0.1,0.5$ and 1 and $t^{*}=3\left(k_{1}=\right.$ 2 day $^{-1}, t=1.5$ day). From figure 2, it is clear that:

For $x>0$ as $\delta^{*}$ decreases the values of $C_{2}^{*}$ decreases. Hence, to obtain minimum values for $C_{2}^{*}$ the values of $D$ or $k_{1}$ must increase. Opposite effects are noticed for the region $x<0$.

The pollutant concentration in zero dispersion case is given by equation (30). This means that the pollutant concentration is caused only by pure convection and rate of pollutant addition along the river. Hence, the downstream limit as $x \rightarrow \infty$ from equation (30) is given by:

$$
\begin{aligned}
C_{3}(x \rightarrow \infty, t)= & \frac{q}{k_{1} A}\left\{1-\exp \left[-k_{1} t\right]\right\} \\
& +p_{1}\left\{\exp \left[-k_{1} t\right]\right\} .
\end{aligned}
$$

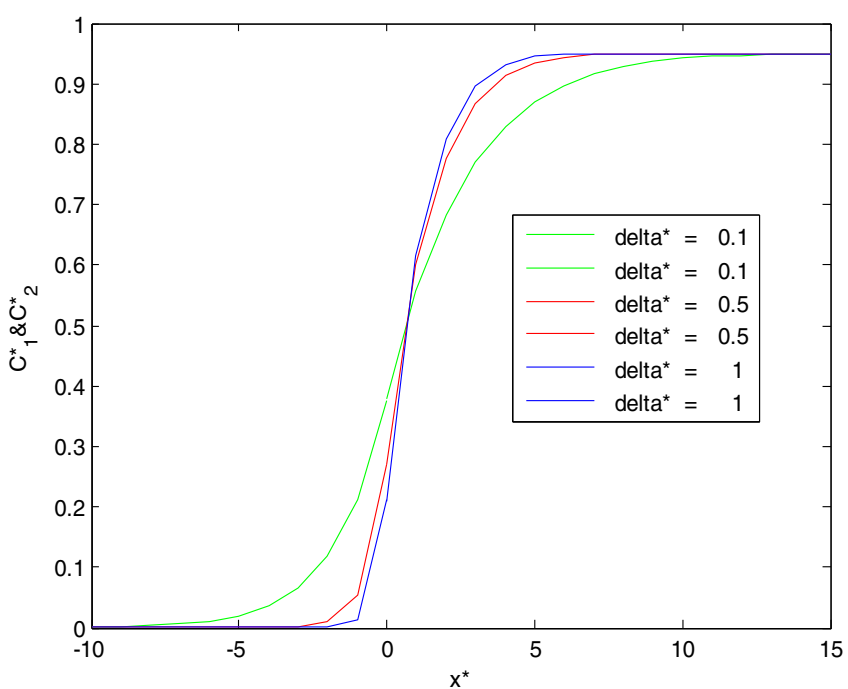

Figure 2. Shows the analytical unsteady state solution with dispersion for $C_{1}^{*}\left(x^{*}, t^{*}\right)$ and $C_{2}^{*}\left(x^{*}, t^{*}\right)$ at different values of delta* $\left(\delta^{*}\right)$ described by equations $(16,17)$.
For the special case when $t \rightarrow \infty$, equation (34) gives:

$$
C_{3}(x \rightarrow \infty, t \rightarrow \infty)=\frac{q}{k_{1} A} .
$$

This result agrees with that obtained by Pimpunchat et al. (2007). In figures 3-5, the values of the parameters $q, k_{1}, A$ and $v$ are taken from Pimpunchat et al. (2007).

Figure 3 shows the variation of $C_{3}^{*}\left(x^{*}, t^{*}\right)$ along the river from source up to sink at different times $t^{*}=6.616 \quad(t=0.8$ day $), 7.443 \quad(t=0.9$ day $), 8.27$ ( $t=1$ day) and 9.097 ( $t=1.1$ day) where $k_{1}=$ 8.27 day $^{-1}, p_{1}^{*}=2894.5$ and $p_{2}^{*}=28.945$. From figure 3 , it is clear that:

As $x^{*}$ increases the value of $C_{3}^{*}$ decreases for any time $t^{*}$, it reaches a constant value near the sink. The effect of the time $t^{*}$ is very small near the

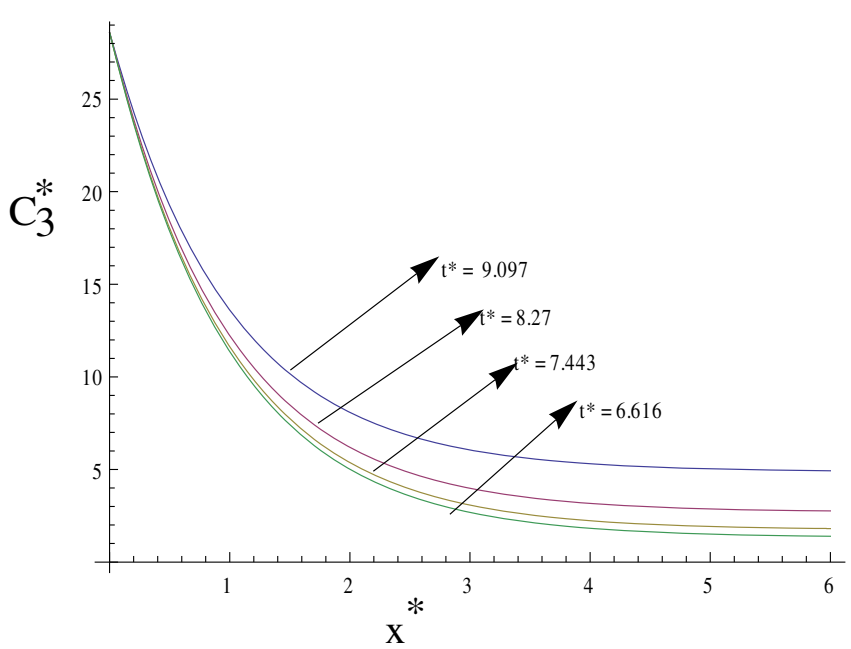

Figure 3. Shows $C_{3}^{*}\left(x^{*}, t^{*}\right)$ along the river from source up to sink at different $t^{*}$ where $p_{1}^{*}$ and $p_{2}^{*}$ are constant as described by equation (32).

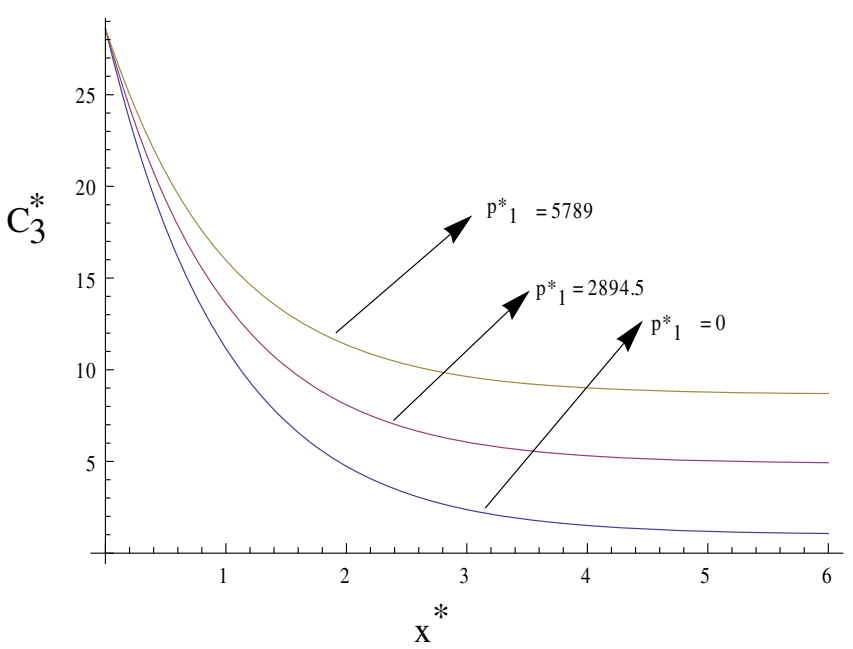

Figure 4. Shows $C_{3}^{*}\left(x^{*}, t^{*}\right)$ as a function of space and time along the river for different values of $p_{1}^{*}$ where $p_{2}^{*}$ and $t^{*}$ are constant described by equation (32). 


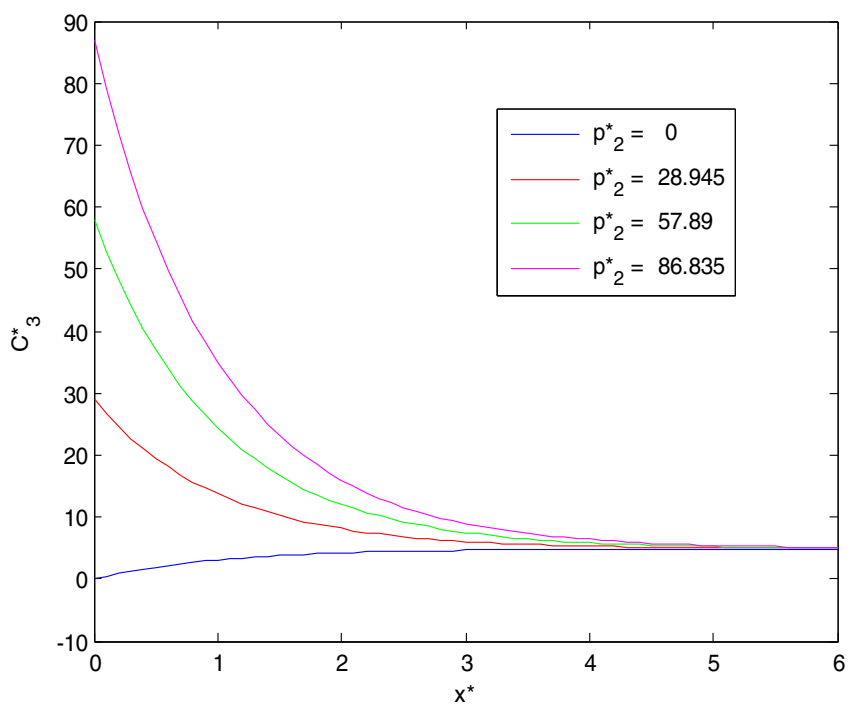

Figure 5. Shows $C_{3}^{*}\left(x^{*}, t^{*}\right)$ as function of space and time along the river for different values of $p_{2}^{*}$ where $p_{1}^{*}$ and $t^{*}$ are constant described by equation (32).

upstream and dominant near the downstream. As $t^{*}$ increases the value of $C_{3}^{*}$ increases at any crosssection of the river.

Figure 4 shows the variation of $C_{3}^{*}$ along the river with different values of

$$
\begin{aligned}
& p_{1}^{*}\left(q=0.06 \mathrm{~kg} \cdot \mathrm{m}^{-1} \cdot \mathrm{day}^{-1}, k_{1}=8.27 \mathrm{day}^{-1},\right. \\
& \left.A=2100 \mathrm{~m}^{2}, p_{1}=0.0,0.01,0.02 \mathrm{~kg} \cdot \mathrm{m}^{-3}\right)
\end{aligned}
$$

where $p_{2}^{*}=28.945$ and $t^{*}=6.616$. From figure 4 , it is clear that:

As expected the minimum value of $C_{3}^{*}$ occurs for $p_{1}^{*}=0$. As $p_{1}^{*}$ increases $C_{3}^{*}$ increases at any cross-section of the river $\left(x^{*}=\right.$ constant $)$.

Figure 5 shows the variation of $C_{3}^{*}$ along the river with different values of

$$
\begin{aligned}
& p_{2}^{*}\left(q=0.06 \mathrm{~kg} \cdot \mathrm{m}^{-1} \cdot \mathrm{day}^{-1}, k_{1}=8.27 \mathrm{day}^{-1},\right. \\
& \left.A=2100 \mathrm{~m}^{2}, p_{2}=0,0.0001,0.0002,0.0003 \mathrm{~kg} \cdot \mathrm{m}^{-3}\right)
\end{aligned}
$$

where $p_{1}^{*}=2894.5$ and $t^{*}=6.616$. From figure 5 , it is clear that:

For $p_{2}^{*}=0$ (for water without pollution) from the upstream of the river $x^{*}=0$, as $x^{*}$ increases $C_{3}^{*}$ increases, this is due to the presence of $p_{1}^{*}$. For the other values of $p_{2}^{*}$ as $x^{*}$ increases $C_{3}^{*}$ decreases. At any cross-section where $x^{*}=$ constant, $C_{3}^{*}$ increases as $p_{2}^{*}$ increases.

\section{Notations and symbols}

$A \quad$ Cross-section area of the river $\left(\mathrm{m}^{2}\right)$.

$C(x, t) C_{1}, C_{2}$ and $C_{3}$ are the pollutant concentrations $\left(\mathrm{kg} \cdot \mathrm{m}^{-3}\right)$.
$D \quad$ Dispersion coefficient of pollutant in the $x$ direction $\left(\mathrm{m}^{2} \cdot \mathrm{day}^{-1}\right)$.

$k \quad$ Half-saturated oxygen demand concen tration for pollutant decay $\left(\mathrm{kg} \cdot \mathrm{m}^{-3}\right)$.

$k_{1} \quad$ Degradation rate coefficient for pollutant $\left(\right.$ day $\left.^{-1}\right)$.

$L \quad$ Polluted length of river (m).

$P \quad$ Laplace transform variable.

$p_{1}$ and $p_{2}$ Initial rate of pollution $\left(\mathrm{kg} \cdot \mathrm{m}^{-3}\right)$ along the river and the rate of pollution $\left(\mathrm{kg} \cdot \mathrm{m}^{-3}\right)$ at the origin respectively.

$q \quad$ Added pollutant rate along the river $\left(\mathrm{kg} \cdot \mathrm{m}^{-1} \cdot \mathrm{day}^{-1}\right)$.

Time (day).

Water velocity in the $x$ direction $\left(\mathrm{m} \cdot\right.$ day $\left.^{-1}\right)$.

Position (m).

Dissolved oxygen concentration $\left(\mathrm{kg} \cdot \mathrm{m}^{-3}\right)$.

(*) Dimensionless quantity.

$\otimes$ Multiplication operation in the convolution theorem.

\section{Conclusion}

Analytical solutions of unsteady pollutant concentration $C(x, t)$ of one-dimensional advectiondispersion equation were derived by using Laplace transformation method. The solutions continue the earlier work of Pimpunchat et al. (2007) (steady state case). From the solution we predicted the pollutant concentration as function of space and time and obtained the variation of pollutant concentration with the parameters of the flow. By writing the solution for the pollutant concentration in the dimensionless form $C_{1}^{*}\left(x^{*}, t^{*}\right)$ and $C_{2}^{*}\left(x^{*}, t^{*}\right)$, we found that both $C_{1}^{*}\left(x^{*}, t^{*}\right)$ and $C_{2}^{*}\left(x^{*}, t^{*}\right)$ depend only on the two dimensionless parameters $q / k_{1} A$ and $\delta^{*}$. We found that $C_{3}^{*}\left(x^{*}, t^{*}\right)$ in general, increases with the increase of one of the dimensionless parameters, $t^{*}-$ time or $p_{1}^{*}-$ the initial pollution of the river, or $p_{2}^{*}-$ the pollution at the source $x^{*}=0$, keeping the two other parameters constant. Numerical studies show that the variation of $C_{3}^{*}$ with time $t^{*}$ is negligible for the special case when $p_{1}^{*}=p_{2}^{*}=0$. From this study, the condition $\frac{\partial C}{\partial x} \rightarrow 0$ as $x \rightarrow \infty$ is satisfied automatically.

\section{References}

Angelakis A N and Rolston D E 1985 Transient movement and transformation of carbon species in soil during wastewater application; Water Resour. Res. 21(9) 1141-1148.

Carslaw H S and Jaeger J C 1959 Conduction of Heat in solids; Clarendon Press, Oxford. 
Djordjevich A and Savovic S 2013 Solute transport with longitudinal and transverse diffusion in temporally and spatially dependent flow from a pulse type source; Int. J. Heat Mass Transfer 65 321-326.

Dobbins W E 1964 BOD and oxygen relationships in streams; J. Sanitary Engineering Division, Proc. ASCE 90 53-78.

Doetsch G 1970 Introduction to the Theory and Application of the Laplace Transform; Springer-Verlag.

Ge S and Lu N 1996 A semi-analytical solution of onedimensional advective-dispersive solute transport under an arbitrary concentration boundary condition; Ground Water 34(3).

Kumar A, Jaiswal D K and Kumar N 2009 Analytical solutions of one-dimensional advection-diffusion equation with variable coefficients in a finite domain; J. Earth Syst. Sci. 118 539-549.

Kumar A, Jaiswal D K and Yadav R R 2011 Onedimensional solute transport for uniform and varying pulse type input point source with temporally dependent coefficients in longitudinal semi-infinite homogeneous porous domain; Int. J. Math. Sci. Comput. 1(2).

Leij F J and Van Genuchten M Th 1995 Approximate analytical solutions for solute transport in two-layer Porous media; Kluwer Academic Publishers; Transport in Porous Media 18 65-85.

Li G 2006 Stream temperature and dissolved oxygen modeling in the Lower Flint River Basin (Athens, Georgia), $\mathrm{PhD}$ thesis, 45p.

Massabo M, Cianci R and Paladino O 2006 Some analytical solution for two-dimensional convection-dispersion equation in cylindrical geometry; Environmental and Software 21 681-688.

Mourad F D, Ali S W and Fayez N I 2013 The effect of added pollutant along a river on the pollutant concentration described by one-dimensional advection diffusion equation; Int. J. Engg. Sci. Tech. 5 1662-1671.

Mikhailov M D and Ozisik M N 1984 Unified analysis and solutions of heat and mass diffusion (John Wiley, New York).
Pimpunchat B, Sweatman W L, Triampo W, Wake G C and Parshotam A 2007 Modeling river pollution and removal by aeration; In: Modsim 2007, International Congress on Modelling and Simulation (eds) Oxley L and Kulasiri D, Land, Water \& Environmental Management: Integrated Systems for Sustainability, Modelling and Simulation Society of Australia and New Zealand, pp. 2431-2437, ISBN: 978-0-9758400-4-7.

Pimpunchat B, Sweatman W L, Triampo W, Wake G C and Parshotam A 2009 A mathematical model for pollution in a river and its remediation by aeration; Appl. Math. Lett. 22 304-308.

Roberts G E and Kaufman H 1969 Table of Laplace Transforms (W.E. Saunders Co., Philadelphia and London).

Savovic S and Caldwell J 2003 Finite difference solution of the one-dimensional Stefan problem with periodic boundary conditions; Int. J. Heat Mass Transfer. 46 2911-2916.

Savovic S and Caldwell J 2009 Numerical solution of Stefan problem with time dependent boundary conditions by variable space grid method; Therm. Sci. 13 165-174.

Savovic S and Djordjevich A 2012 Finite difference solution of the one-dimensional advection-diffusion equation with variable coefficients in semi-infinite media; Int. J. Heat Mass Transfer. 55 4291-4294.

Savovic S and Djordjevich A 2013 Numerical solution for temporally and spatially dependent solute dispersion of pulse type input concentration in semi-infinite media; Int. J. Heat Mass Transfer. 60 291-295.

Shukla J B, Misra A K and Chandra P 2008 Mathematical modeling and analysis of the depletion of dissolved oxygen in eutrophied water bodies affected by organic pollutants; Nonlinear Analysis. Real Applications 9 1851-1865.

Sudicky E A and Neville C J 2008 Solution of partial differential equations (PDE's) using integral transform method; The Laplace transform, pp. 6-12.

Van Genuchten M Th and Alves W J 1982 Analytical solutions of the one-dimensional convective-dispersive solute transport equation; U.S.D.A. Tech. Bull. 1661, 149p. 